Journal of Social Sciences 8 (3): 332-342, 2012

ISSN 1549-3652

(C) 2012 Science Publications

\title{
How does a Culture of Learning Impact on Student Behaviour?
}

\author{
Fransa Weeks \\ Department of Teacher Education, \\ School of Education, College of Human Sciences, \\ University of South Africa, P.O.Box 392, Pretoria, South Africa
}

\begin{abstract}
Problem statement: Despite the need for a culture of learning in South African schools, research reveal that it is not generally encountered. Research also indicates the manifestation of student behavior problems constraining effective learning. Approach: This research study was directed at determining if a link existed between behavior problems and a lack of a culture of learning. The research approach adopted constituted a literature study and a qualitative based, narrative inquiry at a school within a traditionally disadvantaged community. The literature study was undertaken to gain an understanding of the concept "culture of learning" and its impact as a behavioral determinant. Caring schools as a means to address the problem formed part of the study. Results: Important research findings relate to the correlation between characteristics that give rise to behavioral problems and those associated with a lack of a culture of learning, the role played by "caring schools" in nurturing a culture of learning and the importance of addressing students" emotional needs for dealing with behavioral problems. Conclusion: The significance of the research is the guidelines proposed for dealing with behavior problems by establishing a culture of learning. Recommended is in-service training of all key stakeholders in the dynamics of establishing a culture of learning and the realization of learner's unmeet emotional needs.
\end{abstract}

Key words: Behavioral problems, increasing occurrence, provides guidelines, currently available, important findings emanating, traditionally disadvantaged

\section{INTRODUCTION}

South African research studies reflect a decline of a culture of learning in schools (Pillay, 1998; Ngidi and Qwabe, 2010; Niemann and Kotze, 2006; Kruger, 2003; Matoti, 2010). Various causative factors are mentioned, ranging from the legacy of "apartheid" to stakeholders such as parents, teachers and students, not collaborating to establish such a culture (Christie, 2010; Roy, 2007). So for instance Deventer and Kruger (2002) claim that "one of the most important issues that faces education in South African schools today, is the restoration of a sound culture of learning and teaching. The majority of schools continue to reflect characteristics of a poor culture of learning and teaching". Haystack and Lethoko (2001) similarly argue that "one of the main goals in education today, in South Africa, is to restore the culture of learning and teaching in schools with the net result of improving examination results in the matriculation (school leaving) examination and the general standard of education". It is within the context of this reality that former South African President Mbeki (1997) urged educational institutions and teachers to "ensure that the culture of learning and teaching is developed in institutions and schools".

Research undertaken by Pillay (1998) reveals that the majority of schools, of the former education departments responsible for Black education in South Africa, is characterized by a high failure rate, a lack of discipline, low morale and an anti academic attitude amongst students. The researcher goes on to claim that the situation has little changed since South Africa became a democratic dispensation in 1994 and the ongoing turmoil encountered in these schools is underscored by a failure to establish a culture of learning within the schools concerned (Pillay, 1998). The destructive social impact of unemployment, poverty, crime and violence within the communities concerned is considered to play a role in shaping the cultural context that exists within the schools and consequently hamper the establishment of a culture of learning within the classroom and school (Pillay, 1998).

Academic performance seems to have become the yardstick by which the existence of a "culture of learning" in schools is measured. This fact is illustrated by the following comments on the matriculation results (school leaving examination) of 2010: Yeld (2011), at 


\section{J. Social Sci., 8 (3): 332-342, 2012}

the University of Cape Town, pointed out that "the Minister of Basic Education, Angie Motshekga has been careful in the phrasing of all her statements about the pass rate. It might not be an improvement in quality, just an improvement in the pass rate (quantity)". Williams (2011) reflecting on the 2010 matriculation (final examination) results, similarly concluded that:" The examinations were marked more leniently than previous years. The marks were adjusted after marking-known as 'standardization'-a mass standardization".

With the accentuated focus on academic performance however, the other related outcomes of a culture of learning in schools have largely been overlooked, a case in point being its impact on the behavior of students, with the result that no findings on the impact of a culture of learning on problem behavior can be traced.

Eaker and Keating (2008) in a similar vein, contends that "the challenge of changing culture is the challenge of changing behaviour, of persuading people to act in new ways"-not only referring to the changed behaviour patterns of the members of the learning community, but to the problem behaviour that exists at schools where no culture of learning is established. Jacobson (1996) highlights the importance of a "culture of learning" when he maintains that "learning a new culture is at least in part learning a new self".

Behaviour problems /challenging behaviour, within the South African school system, has become a major problem, cited examples being stabbing of students, common and sexual assault, drug possession, carrying of dangerous weapons and suicides, to name but a few (IOLN, 2008; Pillay, 1998). The cited IOC report claims that the South African Human Rights Commission found that over a fifth of sexual assaults take place at school. Seven year old children are apparently playing a game called "rape me". Violent assaults on teachers are also on the increase-recently it was reported that a student in Soweto, had stabbed his teacher with a knife. Wet (2003) cites newspaper reports when she contends that "students are violent, heartless and immoral, typically without conscience, of feelings". Clearly the occurrence of behaviour problems in South African schools is a reality (Ward et al., 2007).

With the prevalence of behaviour problems in certain South African schools, it is hardly surprising that academic performance of matriculation students is "not good enough" and "we are not going to get the accountants and engineers we need with these results" (Bloch, 2011). Past president Mbeki (1997) is also on record as lamenting the lack of a culture of learning in many schools, claiming that "it is only through the acquisition of knowledge, the production of engineers, scientists, doctors and teachers that we shall be able to conquer the scourge of poverty, disease and under development, which is the lot of our people today".

The question posed therefore is whether the establishment of caring schools and consequently a culture of learning in these schools can be regarded as a possible solution for dealing with behaviour problems and the enhancing of academic performance.

Finding and answer for this question is a primary objective of this research study. The methodology used in conducting the research is analytically descriptive and consequently qualitative in nature. It constitutes a literature research aimed at identifying and clarifying the essential characteristics of the concepts: "culture of learning", "learning community", "caring schools" and "behaviour problems". The causative factors impeding the nurturing of a culture of learning in schools is also briefly explored. The empirical research constitutes a narrative enquiry conducted at a South African school situated within a rural environment and a traditionally disadvantaged community setting. In the final instance the insights gained from the empirical study are correlated with the insights stemming from the literature review.

\section{Concept clarification:}

A culture of learning: Sedibe (2006) in researching the concept "culture of learning" concludes that "no uniformity exists as to its actual meaning". A literature review reveals a diversity of definitions as to the concept and its attributes. Zulu et al. (2004), suggest that the term "culture of teaching and learning refers to the attitude of educators and learners towards teaching and learning and the spirit of dedication and commitment in a school which arises through the joint effort of school management, the input of educators, the personal characteristics of learners, factors in the family life of students, school-related factors as well as social factors". Embodied in this definition is the notion of a broad community of role players, as well as contextual factors that are instrumental in the emergence of a culture of learning. Chisholm and Vally (1996) in defining the concept as "bringing about of the conditions and disciplines of compulsory schooling to bear on teachers and students, regular attendance, punctuality and acceptance of authority" focus on the outcomes of its disciplinary determinants. Claxton and Lucas (2009) in contrast refer to the "habits of mind" that "underpin a generic and open-minded attitude to learning". Taylor (2010) contends that "by changing the culture of the school and district to one focused on all students learning, student achievement will increase". Central to these definitions are cultural attributes, 


\section{J. Social Sci., 8 (3): 332-342, 2012}

engender through social interaction that give rise to conditions for effective learning.

With the preceding discussion in mind the following are identified as constituting typical characteristics of a culture of learning within the literature, namely (Anderson and Kumari, 2009; Bowen, 2005; Sabah and Orthner, 2007):

- A multilevel learning environment, in which learning opportunities are part of all activities

- A learning community, engendering shared responsibility and purposeful behaviour to achieve school organizational outcomes

- A different mindset found among teachers, they are caring, prepared and determined to perform their duties, thus creating conditions conducive for student learning. They navigate their own and their student's "inner landscape" by literally learning to mentally and spiritually "dance together" with their students

- Networks of collaboration are established, among all stakeholders, in order to facilitate learning

- A context is crafted where students attend school, are punctual, accept authority and feel safe

- The availability of physical resources, geared for creating a stimulating learning environment

- Clarity exists as to the school mission and values, which are supported by all

- Principals who as leaders engender a context of trust, mutual respect and understanding

- Parents establishing a partnership with teachers

It is suggested that collectively these characteristics define a culture of learning and it is further contended that most definitions attributed the concept incorporate aspects thereof.

Learning community: It is the contention in this study that if a culture of learning has not been established in the hearts and minds of community members, is it a school or some similar form of social construct, it will be extremely difficult to engender a sense and endeavour of learning. An important trend that emerges within the literature is the need for collaboration, joint exploration and ongoing learning in finding answers for the complex questions confronting communities. The learning organisation or community has its origins in the research and writings of Senge (2010), who defined the learning organisation (school) as one in which "people continually expand their capacity to create the results they truly desire, where new and expansive patterns of thinking are nurtured, where collective aspiration is set free and where people are continually learning how to learn together". According to Senge (1994) the school is encapsulated within this broader definition of a learning community, which he defines as "the learning environment within which the school operates".

Bowen (2005) similarly define the learning community as "an organization in which all members acquire new ideas and accept responsibility for developing and maintaining the organization". It focuses on "harnessing experiences of the members and one in which members work together, mutually understanding each other, yet respecting the diversity of one another". The learning community discussion incorporates typical characteristics dealt with in defining a culture of learning. The two concepts are for all practical purposes intertwined.

Caring learning schools: Noddings (1991) emphasises that caring implies relations, such as in the collective learning that takes place in learning schools, expressed "in its most basic form a connection or encounter between two human beings-a carer and a recipient of care or cared-for." The condition for the relation to be qualified as one of caring implies that each party must contribute to the relationship in characteristic ways. It is suggested by Noddings (1991) that "feeling something for the other person, does not qualify it as a "caring relationship", but as "a state of consciousness, characterised by engrossment and motivational displacement". Real caring implies that people will "really hear, see or feel what the other person tries to convey" (Noddings, 1991). Caring does not imply a set of specific behaviours; it is a way of relating with somebody else. Noddings (1991) maintains that "an approach to education that begins with care is not, antiintellectual. Part of what we receive from others is a sense of their interests, including intellectual passions. Caring teachers respond differently to their students".

Bowen (2005) regard the caring component of learning organizations, as "sentiments-the glue that keeps the team together". The authors regard the following as aspects of "sentiments" applicable to all team members on different levels: verbal expressions of positive regard, free flow of emotions, encouragement and support, reinforcement of internal integration and harmony amongst team members, respect, trust and optimism. Fullan (Kis and Konan, 2010) supports the views of Bowen (2005) in arguing that "in a learning school, the individuals' emotions, feelings and mental models have to be shared to build mutual trust".

Murdock and Miller (Woolfolk, 2010) maintain that a correlation exists between the academic 


\section{J. Social Sci., 8 (3): 332-342, 2012}

motivation of students and their perceptions of how caring their teachers are. Davis (Woolfolk, 2010) defines "caring" relating to teachers caring for their students, as a teacher who will not "give up on a student ... who will demonstrate and teach kindness in the classroom". Woolfolk (2010) connects caring attitudes towards students by a teacher, with "personal caring", which implies "a patient, respectful, humorous, willing to listen teacher" who is interested in the learner's issues and personal problems, although high but reasonable academic expectations exist. Noddings (1991) draws attention to the impact of caring teachers, when he contends that "caring is the bedrock of all successful education and contemporary schooling can be revitalized in its light".

A caring environment in the classroom and in the whole school, promotes emotional well being. Smith and Foster (2002) defined emotional well being as "one's ability to relate to other people, feel comfortable with self, cope with disappointments and stress, solve problems, celebrate success and make decisions. The foundation of emotional well-being is positive self esteem". Self-esteem is enhanced when caring is practised -both the selfesteem of the caregiver as well as the person who is being cared for (Bach and Torbet, 1982). In fact, Bach and Torbet (1982) stress that academic and personal "selfrealization is only possible through caring for others". Slavin (2011) supports the foregoing thoughts of Torbet, when he explains that self-realization/selfactualization implies that it is "characterized by the acceptance of self and others, spontaneity, openness, relatively deep but democratic relationships with others, creativity, humor and independence-in essence, psychological health".

Caring schools are clearly important in helping students to achieve success through actualising their full potential. This fact implies that if South African schools and, specifically South African Departments of Education, do not make a paradigm shift, by focussing on covert factors (e.g., students' unmet emotional needs, which necessarily embeds the notion of "caring") instead of focussing mostly on overt factors such as HIV/Aids programmes and adjustments to matriculation (final examination) pass rates, the possibility exists that students will never actualise their full potential. Westman (2011) (undated: Internet) argues that "once we learn to fill these emotional needs, we will see a decline in violence, crime, suicide, depression and all forms of unhealthy behaviour".

The importance attributed to caring schools, in this study, stems from its relevance as a means to address behaviour problems in schools by inculcating a culture of learning, as well as the fact that the ACTCPCA
(2007) have identified the following characteristics, amongst other characteristics, as synonymous to "effective schools" where a culture of learning exists:

- Teachers who are sensitive to individual student needs

- A welfare system within the school system, which supports the development of students to their full potential and which is sensitive to individual student's needs

- Parent participation and community involvement

- An environment conducive to learning; and

- Effective behaviour management policies supported by a strong student welfare system

Behaviour problems: A lot of debate exists on the clarification of the concept behaviour problems (Parsons et al., 2001). Manifestations of emotional and behavioural disorders (Woolfolk, 2010) are listed in the Diagnostic and Statistical Manual of Mental Disorders (DSM-IV-TR) as anxiety disorders, disruptive behaviour disorders, eating disorders, mood disorders and tic disorders. Avramidas, Bayliss and Burden (in Woolfolk, 2010) explain behaviour disorders as "behaviours that deviate so much from the norm that they interfere with the child's own growth and development and/or the lives of others".

The following characteristics of emotional and/or behavioural problems have been identified (Eggen and Kauchack, 2012; Santrock, 2001; Slavin, 2011; Venter and Rambau, 2011; Woolfolk, 2010), namely: Learners who are continuously depressed, or who are constantly experiencing constant feelings of unhappiness, who act with aggression, do not behave according to ethnic norms and values, experience difficulties in relating socially to other students and teachers, suffer from a negative self concept and are frequently playing truant.

Causative factors leading to the non-existence of a "culture of learning" in South African schools: South African research tends to have primarily focus on black township or rural schools. The following conditions, which are not conducive to a "culture of learning", appear to be prevalent at these schools (Kruger, 2003; Lethoko et al., 2001; Ngidi and Qwabe, 2006; Zulu et al., 2004).

Scholastically: Poor academic results, overcrowded classrooms, limited language proficiency, lacking numeric and literacy skills, a school high dropout rate, feelings of fear and insecurity. 


\section{J. Social Sci., 8 (3): 332-342, 2012}

Home circumstances: Inadequate housing, no facilities to study, lack of proper nutrition and health, poverty, breaking up of the family, absence of a father figure.

School facilities: Poor school infrastructure and lack of resources, facilities and equipment.

Principal: Poor school administration and management, bureaucratic school structures, principal mistrusted and not respected by staff members, autocratic decision making hierarchy, collapse of authority in schools, tension and poor relationships between school community role players and a lack of a culture conducive to learning.

Teachers: Uncommitted and not passionate about teaching, no spirit of dedication and commitment, unprepared to present lessons, unprofessional conduct, absent from classes, low levels of morale, inadequate staffing, unable to maintain student discipline and tend to be under qualified, exhibiting a non caring attitude towards students.

Parents: Non supportive, little parental care and involvement, parents themselves illiterate, little intellectual stimulation offered to children, not involved at school as a partner in the education of their children.

Students: Low morale, unmotivated to study, lack self discipline and reflect problematic behaviour trends, dodge classes, disrespect teachers, passive towards learning, experiencing feelings of insecurity, attend school irregularly, who are dependent on and abuse alcohol and substances, who act out in violence and vandalism.

Behaviour problems occurring in schools: Irregular school attendance, substance and alcohol abuse, vandalism, violence and criminality

\section{MATERIALS AND METHODS}

The approach adopted for the research study was analytical, descriptive and consequently qualitative in nature. The research constituted two fundamental components, namely a literature review and a narrative inquiry research design. The contemporary literature review provides the foundation for the empirical study and the narrative enquiry brings the correlation between theory and practice into the spot light, as the concluding findings.

Gorman et al. (2005) describe a qualitative design as "a process of enquiry that draws data from the context in which events occur, in an attempt to describe these occurrences, as a means of determining the process in which events are embedded and the perspectives of those participating in the events, using induction to derive possible explanations based on observed phenomena". It is considered to be a design that is in line with the objectives of this research study. An important assumption of the qualitative research design, according to Gorman et al. (2005), is that the meaning of events, occurrences and interactions can only be understood through the eyes of actual participants, in specific situations. Within the context of this research study the specific situation is that which exists within the school and community setting concerned.

In effect a narrative inquiry forms part of a broader field of qualitative research, it is defined by Atkinson and Delamont (2011) as an "inquiry process of understanding a social or human problem based on building a complex, holistic picture formed with words reporting detailed views of informants and conducted in a natural setting". In the context of this study the narrative enquiry is directed at soliciting the views, perspectives and insights of the respondents, educators and students, at a rural school within a traditionally disadvantaged community setting. As such it constitutes an insight based research study. It is suggested that the adoption of the research design lends itself to being able to discover the hidden aspects encapsulated within human experience and therefore gain a better understanding of the underlying issues confronting educators in dealing with students' behaviour problems and the dynamics involved in engendering a culture of learning.

The narrative case study enquiry was undertaken at a South African secondary school, situated in a rural, traditionally disadvantaged setting. The school in question is deemed to be rather unique in that it has risen above its contextual situation to not only establish a culture of learning within the classrooms and school, but also in serving as a role model for other schools that exist within similar contextual conditions. The school does not experience a continuous occurrence of serious behaviour problems-if a behaviour problem appears to be present, it is dealt with on a preventative level by calling in all the parties involved and by discussing strategies to deal with the problem. Good communication exists among all stakeholders, with parents, taking ownership as partners in the education of their children. A strong focus exists in relation to academic excellence and the profile of values that the school adheres to, these have proved to be quite successful in dealing with behaviour problems.

Neither the school in question nor the respondents' interviewed are identified, as the information obtained was considered to be of a sensitive nature. Identifying of the respondents and the institution concerned held 
the risk that any negative comments would have been compromised. The respondents interviewed consisted of educators and students, as well as the principal. The researcher observed tuition by different teachers, the objective assessment according to the criteria depicting a culture of learning, namely:

- The classroom climate conducive to learning

- Students focussed on gaining control of the learning content and of achieving the envisaged outcomes

- The students keen on learning new facts

- The teacher inspire the students to do research on their own

- The student/teacher relationship professional, caring, supportive, genuine and warm

- The learning taking place in the classroom and the values maintained by students and the teacher during the teaching process, in line with the vision and mission of the school

- The teacher provide students with skills to act resilient in terms of future problem situations

- The teacher create and role model the attitude of "every opportunity can be an enjoyable learning opportunity

- The teacher plan and present lessons in terms of students' abilities, temperament types, learning styles matching up with his or her teaching styles

A focus group interview, with senior students focussing on the criteria of a culture of learning and how the students regard a "culture of learning' relating to their school, has been conducted.

The questions asked were semi-structured and open-ended, allowing the respondents to deviate so as to learn from their personal experience, insights acquired in practice and personal views. It is acknowledged that the information obtained reflects the experience of the respondents within the specific context of the school in question and that it is not possible to extrapolate the findings as being applicable to all other South African schools. The findings do however present a pattern that could serve as a means for verifying the theoretical insights acquired from the literature review.

\section{RESULTS AND DISCUSSION}

Blum (2005) asserts that "scientific evidence demonstrates that increased student connection to school decreases' absenteeism, fighting, bullying and vandalism while promoting educational motivation, classroom engagement, academic performance, school attendance and completion rates". What Blum refers to as increased student connection is in fact nothing other than the definitive attribute of a caring school. Visser (2000) argues that "inclusive/caring schools" recognise and meet students' emotional needs, in that the teacher spends time listening to what pupils have to say. Schaps and Lewis (1999) provides a student's comment about a caring school: "My classmates care about my work just as much as their own. My school is like a family. I feel I can talk to the teachers in this school about things that are bothering me". This comment clearly suggests that behavioural problems are less likely to be manifest in caring schools. Students' unmet emotional needs, according to Pringle (1986) model, acts as a causative factor of the previously listed behaviour problems in South African schools. In the ensuing discussion these unmet needs will be assessed in terms of what a culture of learning can offer in meeting these needs. Slavin (2011) highlights Maslow's theory, by pointing out that if a student experiences feelings of not being loved or of being incompetent, the student will not demonstrate a strong motivation to actualise his or her full potential but rather will "blend in" with the crowd. A teacher who is able to make students feel accepted and respected as an individual, will stimulate a student to become eager to learn for the sake of learning and the student will eventually develop the self-confidence to risk being open and accessible to new ideas, to being creative in his or her own unique way and to achieve personal goals-thus the teacher will be attending in a spontaneous manner, to the behaviour problem of "underachievement".

Pringle (1986) in a similar vein as Maslow, with his hierarchy of needs (Slavin, 2011), maintains that when the following identified emotional needs are met, the behaviour problems exhibited by students will be far fewer or even eliminated and the student will feel positive about him or herself:

Need to feel loved/cared for: The student can experience "love"/caring if teachers care for their students, listen to them and create the feeling and impression that people are concerned about him or her. The student feels understood, accepted and experiences a sense of cohesion and mutual understanding, which paves the way for engendering a feeling of being cared for.

Need to feel safe: A "safe" school contributes towards satisfying students need to for security. It's a context where students experience feelings of security because they feel part of a caring community. Students know they are not on their own, when confronted by problematic situations. Trial-and-error is regarded as learning opportunities that stimulate risk taking and 


\section{J. Social Sci., 8 (3): 332-342, 2012}

accepting new challenges. The absence of competition frees students from feelings of insecurity. The learning school is a safe, orderly and disciplined institution and students knows what to expect and what behaviour is appreciated. Have control over own academic progress, creates a feeling of pride and being in control, which is associated with feelings of security. Networking and collaboration as key themes in a learning school, acts as safety nets to the student.

Need to experience responsibility: Opportunities for taking responsibly is possible within the learning school, as the students are encouraged to take control of their own progress, as well as contribute in finding solutions for problems encountered. Keeping to the stated norms and values, as role modelled by adult team members, also offers students an opportunity to act responsibly.

The need for new experiences: The need for new experiences is purely cognitively linked and focuses especially on how to stimulate the student. This need can be fulfilled in every aspect of the learning school, as a "culture of learning" is focussed on equipping the student with knowledge and strategies for addressing problem situations. It also engenders creativity and out of the box. Experiencing success boosts the self-image of learners, providing them with feelings of security.

The need to be praised and recognised: Against the background of collective learning, the philosophy pertained in learning schools, namely that "all children can learn", demonstrates a caring attitude that paves the way for the student to be praised and recognised. The belief that all students are uniquely gifted creates opportunities for praise and recognition. The fact that appreciation is being showed for efforts of co-team members, as part of the value system upheld in the learning school, allows also for satisfying the need of the student to be praised and recognised.

It would appear that a caring school that has engendered a culture of learning constitutes a real possibility that may assist in combating the spiral of challenging behaviour in South African schools. The underlying rationale is one of addressing the psychological and emotional needs that trigger challenging behaviour within the context of caring schools.

An analysis of the interviews conducted with teachers as part of the empirical research reveals an interesting pattern, with most of the teachers interviewed indicating that they were of the opinion that the school had in fact established a culture of learning and caring in both the classroom and the school itself. Asked to describe the culture the following characteristic were identified from the teachers' responses:

- A positive atmosphere where students can learn; teachers can teach and parents can actively participate as partners of teachers in the education of their children

- An atmosphere of cohesiveness, as the staff members and students regard themselves as being part of an "excellent school" striving for success and to be the best school among other schools

- A school where students and staff members can feel safe, although the school is a part of a rural area

- A solid value system (based on Christian values), guiding the behaviour of students and teaching staff manifesting in regular attendance, punctuality, acceptance of and respecting authority

- A general feeling among teachers of being motivated-no spirit of low morale is present

- Good academic results achieved by most students

- Students are focussed on their future and realise that they need to further their studies after they have completed their school career

- Alumni students of the school, keep on returning to the school and are utilised as motivational speakers in order to inspire younger learners

- If serious behaviour problems, such as criminality, violence, vandalism or substance abuse, occur at the school - preventative strategies are in place

- A spirit of dedication, excellence and caring prevails among teaching staff and students

- A climate, conducive to teaching and learning is created

- A social system which supports learning in a positive learning context is envisaged and developed

- A shared sense of purpose among all stakeholders and students

- Educators are passionate about students and their contribution as role models to students

- Educators are living examples of a "culture of learning" by furthering their own qualifications and by enrolling for workshops and courses to guarantee quality education

- No labelling of students is allowed-equal opportunities for all students to develop their potential and abilities are expected of teaching staff A clear code of conduct exists, based on a Christian value system

- Enabling learner resiliency on a cognitive and emotional level in order to face a turbulent world 


\section{J. Social Sci., 8 (3): 332-342, 2012}

- Nurturing the matching up of positive learning styles and teaching styles in order to accommodate each students and teacher's teaching and learning style as well as the temperament type of each learner and teacher

- Participative learning versus "telling" education

- A clear cut vision and mission that everybody is familiar with and abides by

- Shared leadership by the principal instead of an authoritative, autocratic style of management

- Creating a sense of "each opportunity is a learning opportunity" among teaching staff and students

- An accentuated focus by the principal, teaching staff and other stakeholders on the assessment of teaching staff and students' self-knowledge, aims for him or herself, as well as the assessment of the self image and measures to prevent teaching staff from harming the self image of students

- No unethical or unprofessional behavior of educators or labeling of students by educators, or any negative comments, harming the self image of learners, are allowed

- Creating a culture of learning together with a culture of resilient students who are ready to face the world and to thing cognitively (and emotionally) about possible solutions to problems that might come their way

- The school is, in the eyes of members of the community, regarded as a school which makes a difference to the lives of the children from the community-a school where students can learn and teachers can teach

Although a culture of learning exists in terms of the above criteria in the classrooms and school, teachers have highlighted the following general (which can be present in schools where a culture of learning doesn't exist) and special problem areas (typical of this specific school), concerning some students, that needs to be followed up more extensively, on an individualized basis with the specific students concerned:

- More involvement of working parents

- Orphaned students who need support networks

- Alcohol abuse of parents

- Students who are deprived of the attention and love of parents

- Parents who are fighting a lot

- Poor living conditions, lack of fulfillment of basic needs, although bursaries/scholarships have been organized for the students

- Making students responsible for younger siblings and to carry out household chores, while they should have been devoting their time and energy to their schoolwork

- Parents are illiterate and cannot assist students with their homework

- Students are being reared by grandparents who cannot assist students with their homework

- Students lack basic technology

- Language barriers causes students not to be able to excel at school as they do not understand English as medium of instruction

- Divorced and single parent households and their typical problems

- Students are "out of touch" with their families and extended families, as they are dumped by parents in hostels and in bed and breakfast venues

The above factors need to be addressed to circumvent behavior problems that could develop. These factors hold the potential for negative factors to arise such as feelings of rejection, not being loved or cared for by parents, feelings of being a nuisance to the parents and feelings of insecurity. As they are "out of touch" with their families and extended families and doesn't know where they belong, the manifestations of unmet emotional needs can, as maintained by Pringle, trigger behavior problems.

Linked to the preceding discussed factors and their behavioural manifestations, teachers listed the following behaviour patterns, occurring in the classroom:

- Gaining attention by acting disruptively

- Daydreaming and not concentrating on the learning content

- Attitudinal problems manifesting in a "don't care" attitude

- Students acting irresponsible in terms of the completion of tasks

- Students exhibit a greater interest in their social activates and neglecting academic tutorials

- Daring attitudes exhibited by students, as the parents are not involved in their schooling

- Postponing studying for examinations and tests until the very last minute

- Students experiencing a sense of low self esteem

- Attention deficit problems and hyperactivity as manifestation of the problem

Transcripts of the interviews with teachers reveal a pattern of agreement as to a culture of learning's impact on the behavior of students. Suggested by the voices of participants, are that students will be: 


\section{J. Social Sci., 8 (3): 332-342, 2012}

- Self-motivated and disciplinary problems will be almost non-existing

- Taking pride in their school work and encourage others to perform

- More focused on their goals and to achieve knowledge, no time to idle

- Will be experiencing a boost of their self confidence

- Ready to succeed academically in society

- Used to learn/study and he or she will show respect for elders

- Feeling that they are loved, accepted, recognized, respected and consequently tend to act responsibly"

- Experiencing that they are in a positive, good environment, where discipline is encouraged

- Learning on all levels, which will have a profound impact on learner behavior

- Able to achieve the right combination of academic, sport, culture and social learning

The focus group interviews revealed that students felt that they needed to excel academically to a far greater extent if they were to compete with the top schools in South Africa. To achieve this outcome, students mentioning factors such as the changing of the curriculum, to include subjects that are related to what they termed to be the "real world" outside the school. The students wanted to gain knowledge and skills on topics which will add to their resume of capabilities such as how to build a house, how to start your own business and how to conduct meetings. They were of the view that the way that lessons are presented should be adjusted to be more in line with the latest technology, enabling students to become familiar with and to utilize technology more fruitfully in their studies.

\section{CONCLUSION}

With escalating statistics on the occurrence of behaviour problems in South African schools, as well as the degree of seriousness of behaviour problems encountered, the South African Department of Education will need to create strategies to establish a "culture of learning" in all schools. Schools can no longer suffer from "learning disabilities" (Senge, 2010), seeing that a "culture of learning" holds the potential to address both the behaviour problems and the unacceptable academic performances of students. The unmet emotional needs of students triggering behaviour problems can be met spontaneously within caring schools that have embodied a "culture of learning".
From the findings of the narrative case study, it is evident that all the respondents agreed that the establishment of a culture of learning in the classroom and in the school, does impact on behaviour. A culture of learning offers a student, who might be experiencing unmet emotional needs within his or her relationships an opportunity to change from being a "nobody" to a "somebody", as emotional needs are being met within the relationships that emerge in a learning community. A culture of learning therefore holds the potential to address both the behaviour problems and academic performance of students.

The way forward: An urgent need for both addressing the reality of behaviour problems occurring at South African schools and finding new strategies to deal with this phenomenon effectively is needed as well as the fact that a culture of learning needs to be established in all South African schools in order to actualise the full potential of all students. If the establishment of cultures of learning in all South African schools can act as a solution to the continuous occurrence of behaviour problems within South African schools, this possibility should be explored on a national basis.

Future research on a step by step programme, linked to conditions existing in South African schools, on how to establish a culture of learning is urgently needed. Consultations followed up by establishing contracts with the Education Departments of the different provinces in South Africa should follow up on the presentation of a uniform step by step programme detailing how to establish a culture of learning, while taking into consideration the satisfying of students unmet emotional needs

In service training of principals, teachers and other stakeholders, such as board members of schools, community leaders and especially parents of students, should be instigated. The purpose of the training is to ensure that every stakeholder takes ownership of the actualising of the full potential of all students in a collaborative sense to ensure that the vision and mission of schools are actualised. Schools will thus provide communities with the leaders of tomorrow, namely leaders who have become lifelong learners and who have acquired the abilities needed on a cognitive and emotional level, to tackle any future challenges and/or problem situations, as well as to institute caring communities by acting as caring role models to other members of the community.

Special attention in teacher education programmes at South African Universities, should be given to the inclusion of knowledge on the importance of establishing a culture of learning in schools, as well as 
how to establish a culture of learning and the satisfying of the unmet emotional needs of learners within their relationships as members of the learning community.

This study can contribute to being a "wake up call" for educators to reconsider the value and impact of the establishment of a culture of learning in schools, by focussing not only on the academic performance of students, but to also to take note of the impact of emotional needs on the academic performance of students, something which has never come to light in the past. This study can contribute to a successfully driven education programme, presented to Education Departments and Parliament, as a counter effort to the unsuccessful COLTS programme lodged by Education Departments, after past president Mbeki's appeal for the establishment of cultures of teaching and learning in schools.

\section{REFERENCES}

ACTCPCA, 2007. Characteristics of Effective Schools. ACT Council of Parents and Citizens Associations.

Anderson, S. and R. Kumari, 2009. Continuous improvement in schools: Understanding the practice. Int. J. Edu. Dev., 29: 281-292. DOI: 10.1016/j.ijedudev.2008.02.006

Atkinson, P. and S. Delamont, 2011. Qualitative research. Committee on Publication Ethics (COPE).

Bach, G.R. and L. Torbet, 1982. A Time for Caring. 1st Edn., Wellness Institute, Inc., New York, ISBN: 1587410656, pp: 416.

Bloch, G., 2011. Matric results expose truth about education. VUSA, Inc.

Blum, R., 2005. School Connectedness: Improving Students' Lives. Johns Hopkins Bloomberg School of Public Health, Baltimore, Maryland.

Bowen, G.L., 2005. The Reliability and Validity of the School Success Profile. 1st Edn., Xlibris Corporation, Philadelphia, PA., ISBN: 1413475442, pp: 184.

Chisholm, L. and S. Vally, 1996. The Culture of Learning and Teaching in Gauteng Schools. 1st Edn., Education Policy Unit. ISBN: Johannesburg, 1868382206, pp: 67.

Christie, P., 2010. Landscapes of leadership in South African Schools: Mapping the changes. Educ. Manage. Amin. Leadership, 38: 694-711. DOI: $10.1177 / 1741143210379062$

Claxton, G. and B. Lucas, 2009. School as a Foundation for Lifelong Learning: The Implications of a Lifelong Learning Perspective for the ReImagining of School-Age Education. 1st Edn., NIACE, Leicester, England, pp: 28.
Deventer, I.V. and A.G. Kruger, 2002. Educator's Guide to School Management Skills. 1st Edn., Van Schaik Publishers, Pretoria, ISBN: 0627025307, pp: 296.

Eaker, R. and J. Keating, 2008. A shift in school culture: Collective commitments focus on change that benefits student learning. J. Staff Develop., 29: 14-17.

Eggen, P. and D.P. Kauchack, 2012. Educational Psychology: Windows on Classrooms. 9th Edn.,: Pearson, New Jersey, ISBN: 0132610213, pp: 672.

Gorman, G.E., P.R. Clayton, S.J. Shep and A. Clayton, 2005. Qualitative Research for the Information Professional: A Practical Handbook. 2nd Edn. Facet, London, ISBN: 1856044726, pp: 282.

Heystek, J. and M. Lethoko, 2001. The contribution of teacher unions in the restoration of teacher professionalism and the culture of learning and teaching. South Afr. J. Educ., 21: 222-227.

IOLN, 2008. 'Rape me, rape me': The game children play. IOL News.

Jacobson, W., 1996. Learning culture and learning culture. J. Res. Theory, 47: 15-28.

Kis, A. and N. Konan, 2010. The characteristics of a learning school in information age. Proc. Soc. Behav. Sci., 2: 797-802. DOI: 10.1016/j.sbspro.2010.03.106

Kruger, A.G., 2003. Instructional leadership: The impact on the culture of teaching and learning in two effective secondary schools. South Afr. J. Educ., 23: 206-211.

Lethoko, M.X., J. Heystek and J.G. Maree, 2001. The role of the principal, teachers and students in restoring the Culture of Learning, Teaching and Service (COLT) in black secondary schools in the pretoria region. South Afr. J. Educ., 21: 311-316.

Matoti, S.N., 2010. The unheard voices of educators: Perceptions of educators about the state of education in South Africa. South African Universities Vice Chancellors Association, Pretoria, South Africa.

Mbeki, T., 1997. Speech by deputy president Mbeki at the launch of the culture of learning and teaching campaign. Fort Hare University, Alice.

Ngidi, D. and J. Qwabe, 2006. The partnership of parents, educators and principles in creating a culture of teaching and learning in schools. South Afr. J. Educ., 26: 529-539.

Niemann, R. and T. Kotze, 2006. The relationship between leadership practices and organisational culture: An education management perspective. South Afr. J. Educ., 26: 609-624. 
Noddings, N., 1991. The Challenge to Care in Schools: Rethinking the Goals of Education. 1st Edn., College of William and Mary, Williamsburg, Va., pp: 16 .

Parsons, R.D., S.L. Hinson and D. Sardo-Brown, 2001. Educational Psychology: A Practitioner-Researcher Model of Teaching. 1st Edn., Wadsworth Thomson Learning, Belmont, CA., ISBN: 0534557015, pp: 537.

Pillay, D.S., 1998. Parents and principals as partners in creating a culture of learning. University of Zululand, South Africa.

Pringle, M.K., 1986. The Needs of Children. 3rd Edn., Hutchinson, London, ISBN: 0091702518, pp: 190.

Roy, I.J., 2007. Staff developers' perceptions on building a culture of teaching and learning. S. Afr. J. Educ. Higher Educ., 21: 907-918.

Sabah, Y. and D.K. Orthner, 2007. Implementing organizational learning in schools: Assessment and strategy. Children Schools, 29: 243-246.

Santrock, J.W., 2001. Educational Psychology. 1st Edn., Mc Graw-Hill, New York, ISBN: 0072906367, pp: 535.

Schaps, E. and C. Lewis, 1999. Perils on an essential journey: Building school community. Phi Delta Kappan, 81: 215-218.

Sedibe, M., 2006. A Comparative Study of the Variables Contributing Towards the Establishment of a Learning Culture in Schools. 1st Edn., University of Pretoria, South Africa, pp: 684.

Senge, P.M., 1994. The Fifth Discipline Fieldbook: Strategies and Tools for Building a Learning Organization. 1st Edn., Doubleday Currency Publishers, New York, ISBN: 0385472560, pp: 593.

Senge, P.M., 2010. The Fifth Discipline: The Art and Practice of the Learning Organization. 1st Edn., Random House, ISBN: 1407060007.
Slavin, R.E., 2011. Educational Psychology: Theory and Practice. 10th Edn., Pearson, Boston, ISBN: 0137034350, pp: 572.

Smith, W.J. and W.F. Foster, 2002. Restoring a culture of learning and teaching: The governance and management of schools in South Africa. Int. Stud. Educ. Admin., 30: 2-11.

Taylor, R.T., 2010. Leadership to improve student achievement: Focus the culture on learning. AASA J. Scholarship Pract., 7. 10-23.

Venter, E. and E. Rambau, 2011. The effect of a latchkey situation on a child's educational success. South Afr. J. Educ., 31: 345-356.

Visser, J., 2000. What schools need for EBD pupils to be included. Proceedings of the International Special Education Congress, Jul. 24-28, ISEC, pp: 24-28.

Ward, C.L., Martin, E., Theron, C., Distiller, G.B., 2007. Factors affecting resilience in children exposed to violence. S. Afr. J. Psychol., 37: 165187.

Westman, J., 2011. Social problems and unmet emotional needs. JACKIE's Blog.

Wet, C.D., 2003. Free State educators' perceptions of the scope of learner crime. South African J. Educ., 23: $168-175$.

Williams, D., 2011. Pass does not equal future. BDFM Publishers (Pty) Ltd.

Woolfolk, A., 2010. Educational Psychology: Active Learning Edition. 11th Edn., Pearson, Boston, ISBN: 0135094100, pp: 748.

Yeld, N., 2011. Matric results expose truth about education. AVUSA, Inc.

Zulu, B.M., G. Urbani, A.V.D. Merwe and J.L.V.D. Walt, 2004. Violence as an impediment to a culture of teaching and learning in some South African Schools. South Afr. J. Educ., 24: 170-175. 